Regards sur l'économie allemande

Bulletin économique du CIRAC

$88 \mid 2008$

Varia

\title{
Science de la gestion
}

WÖHE Günter, DÖRING Ulrich, Einführung in die Allgemeine

Betriebswirtschaftslehre

\section{(2) OpenEdition}

Journals

Édition électronique

URL : http://journals.openedition.org/rea/1803

DOI : $10.4000 /$ rea. 1803

ISBN : 978-2-8218-0872-0

ISSN : 1965-0787

Éditeur

CIRAC

Édition imprimée

Date de publication : 1 octobre 2008

ISSN : 1156-8992

Référence électronique

"Science de la gestion », Regards sur l'économie allemande [En ligne], 88 | octobre 2008, mis en ligne le 09 décembre 2008, consulté le 22 septembre 2020. URL : http://journals.openedition.org/rea/1803 ; DOI : https://doi.org/10.4000/rea.1803

Ce document a été généré automatiquement le 22 septembre 2020

(C) CIRAC 


\section{Science de la gestion}

WÖHE Günter, DÖRING Ulrich, Einführung in die Allgemeine

Betriebswirtschaftslehre

\section{RÉFÉRENCE}

WÖHE Günter, DÖRING Ulrich, Einführung in die Allgemeine

Betriebswirtschaftslehre, coll. Vahlens Handbücher der Wirtschafts- und

Sozialwissenschaften, 23e éd., Verlag Franz Vahlen, Munich, 2008, 1066 p.

1 On rêverait d'avoir, en France, des manuels de gestion d'entreprise destinés aux étudiants (bachelor et master) aussi 'précieusement' reliés et imprimés sur un très beau papier couché, de surcroît. Il faut dire aussi que c'est là la $23^{e}$ édition DU manuel dont la première édition remonte à 1960. La présente s'est adaptée aux nouveaux modes d'enseignement et d'acquisition du savoir, et pas seulement sous l'angle visuel : les 750 graphiques de la version papier peuvent par exemple être téléchargés sous forme de fichier ad hoc sur le site de l'éditeur. A relever aussi que le premier chapitre, consacré à l'objet comme aux méthodes des sciences du management et de la gestion, figure une présentation de l'évolution de ses approches en Allemagne depuis la fin du XIX siècle. (ib) 